\title{
CHEMICAL AND NUTRITIONAL CHARACTERIZATION OF PERILLA FRUTESCENS SEED OIL
}

\author{
Mohammad Asif, Guru Ram Das (Post Graduate) Institute of Management and Technology, Dehradun, India
}

Received: 1 September 2012, Accepted in revised form: 26, November 2012, Published: 6December 2012

Corresponding author: Dr. Mohammad Asif, E-mail: aasif321@gmail.com

\section{ABSTRACT:}

Perilla frutescens seeds contain saturated fatty acids and unsaturated fatty acids which include the monounsaturated and polyunsaturated fatty acids. These seeds contain approximately $35-40 \%$ oil. The oil of Perilla frutescens contains $\omega-3$ fatty acids (54-64\%), $\omega-6$ fatty acids $(\approx 14 \%)$ and the $\omega-9$ fatty acids (small amount). In comparing to other plant oils, Perilla oil contains one of the highest proportions of $\omega-3$ fatty acids. These polyunsaturated fatty acids are the most beneficial to human health in prevention and control of various diseases like cardiovascular disorders, cancer, inflammation, rheumatoid arthritis etc. This review article describes briefly the benefits and the medicinal uses of Perilla frutescens seeds.

Key words: Perilla frutescens seeds, polyunsaturated fatty acids, $\alpha$-linolenic acid.

\section{Perilla Frutescens التوصيف الكيميائي والذذائي لزيت بذور النبات بيريلا فروتيسينس}

تحتوي بذور النبات بيريلا فروتيسينس Perilla frutescens على الأحماض الدهنية المشبعة والأحماض الدهنية غير المشبعة والتي تثمل الأحماض

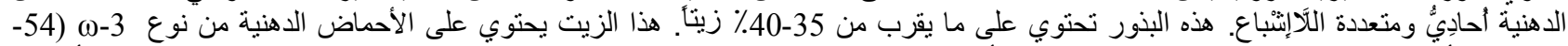

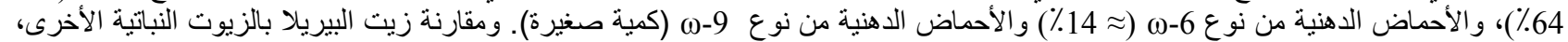

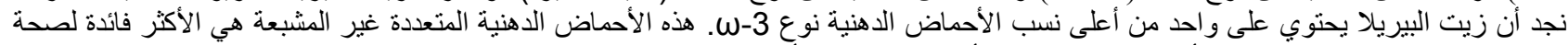

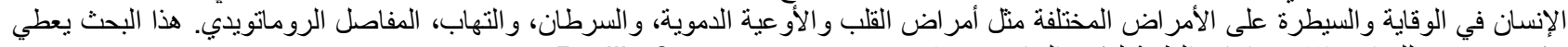

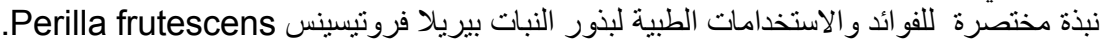
الكلمات المفتاحية: النبات بيريلا فروتيسينس Perilla frutescens ، الأحماض الدهنية المتعددة غير المشبعة، حمض ه لينوليك

\section{INTRODUCTION:}

erilla frutescens (Labiatae) commonly called Perilla is an annual crop. It is native to East Asia and the major producing countries of Perilla are China, Japan, Korea, Thailand, India and other East Asian countries. The herb is about 1 meter high with small flowers, gray brown fruits, and hairy leaves. Cultivation of the plant is carried out in May. Harvesting is usually between the end of September and beginning of October ${ }^{1,3}$ The used parts of Perilla are leaves and seeds. The seeds of Perilla contain $35-40 \%$ of oil. Perilla oil is a light yellow clear and transparent liquid, with aromatic odor and slightly soluble in ethanol. Perilla seed oil is used as cooking oil. Its dry oil used in painting, varnishing and ink manufacturing. The seed cakes are used as animals and birds food ${ }^{3,5}$. Major fatty acids of the oil are unsaturated fatty acids (USFAs) like $\alpha$-linolenic acid (54-64\%), oleic acid (14-23\%), linoleic acid (11-16\%) and the saturated fatty acids (SFAs) (6.7-7.6\%). The
Perilla seeds are small and weight about 4 gms/1000 seeds.

\section{COOKING WITH PERILLA OIL:}

In the diet, Perilla oil is consumed cold as a dressing for salads, pasta and frying. Therefore, it is important to determine the stability of the identified active components when subjected to heat. The major process contributing to the instability of Perilla oil when stored or heated is oxidation $^{6}$. Sufficient exposure and degradation can lead to significant changes in the composition of the oil, and these changes affect its biological properties. Cooking with Perilla oil produces a number of degradation products, with lipid peroxidation occurring to a limited extent. The heating method also affects degradation. Lipid peroxidation products have been linked to cancer and cardiovascular disease. Compared with other oils used for cooking, Perilla oil has MUFAs and PUFAs. This means fewer targets for reactive 
oxygen species (ROS), making Perilla oil more stable and less likely to undergo peroxidation. In addition, Perilla oil contains many antioxidants that reduce lipid peroxidation. Although antioxidants protect Perilla oil from thermal degradation, frying reduces the oil's antioxidative capacity, a particularly important fact when the same oil is used repeatedly. Deep fat frying has both advantages and disadvantages related to olive oil degradation. The low oxygen exposure of the oil and a short cooking time reduce the potential for lipid peroxidation. However, because the oil is more likely to be re-used, accumulation of polymeric compounds occurs as the antioxidant capacity is being reduced. Compared to other oils, olive oil has a relatively long deep-fat frying "shelf-life" and is comparatively more stable than other oils for repeated frying 7 . Because exchange between lipids in the food and the oil occurs during cooking, the type of food fried also plays a role. For example, frying fish increases the oil's instability because the oil becomes enriched with PUFAs, which are more susceptible to oxidative degradation than MUFAs. Although frying foods with a high protein content such as meat, fish, and eggs can potentially produce carcinogenic heterocyclic amines (HCAs), the antioxidants present in olive oil limit the formation of $\mathrm{HCAs}^{8}$.

\section{CHEMISTRY OF PERILLA SEED OIL:}

Perilla is a source of fatty acids that contains both SFAs and USFAs (MUFAs \& PUFAs). Fatty acids having saturated carbon chain are called saturated fatty acid (SFAs), those having single double bond called monounsaturated fatty acids (MUFAs) and those having more than one double bond are termed as polyunsaturated fatty acids (PUFAs). The SFAs of Perilla oil are mainly palmitic acid (PA 5-7\%), stearic acid (SA 1-3\%). The MUFAs content is oleic acid (OA 12-22\%) while the PUFAs content are linoleic acid (LA 13$20 \%$ ), $\gamma$-linolenic acid (GLA 0-1\%), $\alpha$-linolenic acid (ALA 52-64\%) and icosanoic acid (IA 0$1 \%)$. Unsaturated fatty acids are of lower melting point than saturated fatty acids [6-8].

\section{IMPORTANCE OF $\Omega-3, \Omega \quad-6$ AND $\Omega-9$ PUFAS:}

The $\omega-3$ and $\omega-6$ fatty acids are essential fatty acids (EFAs), because these fatty acids cannot be synthesized by the body itself. Instead, we must include them in our diet or through supplements to meet our body demands. $\omega-9$ fatty acids are "conditionally essential", which means that if we have the other fatty acids in our diet, then our body can manufacture $\omega-9$ fatty acids. Otherwise, $\omega 9$ fatty acids must be consumed or supplemented as well ${ }^{9,11}$. Among plant oils, the balance between $\omega-3, \omega-6$ and $\omega-9$ fatty acids must dictate which oil is chosen. Oils which predominate in $\omega-3$ component would be most likely to promote health. Most of them would actually contribute to the imbalance of $\omega-6$ fatty acids because they contain more $\omega-6$ than $\omega-3$. Any amount of $\omega-9$ is beneficial, but in balancing these fatty acids, the $\omega-3$ component is the most important ${ }^{12,13}$. The essential fatty acids (EFAs) of Perilla oil have been associated with benefits in a wide range of inflammatory conditions, heart diseases, colitis/Crohn's disease, asthma, and allergies, antimicrobial, anticancer and various skin conditions. Anti-inflammatory doses of Perilla oil have been shown to reduce the hypertensive and nephrotoxic effects of cyclosporine ${ }^{14,16}$.

\section{CARDIO-VASCULAR BENEFITS:}

$\omega$-3 PUFAs, are mainly exist in the form of docosahexaenoic acid (DHA) and eicosapentaenoic acid (EPA) at a rate of roughly $7-10 \%$ that can help to prevent heart diseases. These two specific $\omega-3$ fatty acids metabolites are inserted in cell membranes throughout the body, where cellular machinery converts them into substances which prevent abnormal clotting, and relax blood vessels and improved ventilatory parameters. These $\omega-3$ rich fatty acids, may lead to prevention of coronary heart disease and decrease blood clotting ${ }^{17}, 18$. In platelets, the cell products in the blood which aid in clotting, $\omega-6$ fatty acids are converted to thromboxane A2 (TXA2). This makes the platelets more likely to burst or degranulate, releasing their clotting substances and cell messengers. These cell messengers constrict blood vessels and cause other platelets to burst-causing a clotting cascade. On the other hand, when $\omega-3$ fatty acids are used in the same machinery in platelets, thromboxane A3 (TXA3) is made, which is inactive ${ }^{17,}{ }^{18}$. Moreover, the $\omega-6$ fatty acids make more inflammatory substances ${ }^{17,19}$. These substances include leukotriene B4, (LTB4), which is a cell messenger responsible for inflammation throughout the body. LTB4 actually causes white blood cells to absorb oxidized low density lipoprotein (LDL) which is rich in cholesterol forming cholesterol plaque on blood vessels. In contrast, when $\omega-3$ fatty acids are used in the same cellular machinery, leukotriene B5 (LTB5) is made which has anti-inflammatory properties. Health demands normal functioning of both systems ${ }^{17,19}$.

\section{ANTI-INFLAMMATORY AND RHEUMATOID ARTHRITIS BENEFITS:}

Perilla oil is rich in the $\omega-3$ fatty acids, on metabolism gives EPA and DHA, which can displace arachidonic acid (AA) from cell 
membranes. These $\omega-3$ fatty acids are also released with AA by phospholipases and act as substrate inhibitors of conversion of AA by cyclooxygenases (COX) and the terminal synthases to the pro-inflammatory oxygenated inflammatory mediators known as eicosanoids. EPA is structurally identical to AA with the exception of its additional n-3 double bond and can be converted to compounds that resemble eicosanoids. In addition to these effects on inflammatory eicosanoid synthesis, Perilla oil have been shown to reduce the production of the inflammatory cytokines IL-1 $\beta$ and TNF- $\alpha$ by monocytes stimulated in vitro. These cytokines are important effectors molecules in inflammatory responses and TNF- $\alpha$ blocking agents are now used widely to treat rheumatoid disease that has proven refractory to less expensive therapies. In vitro studies have also shown inhibition of release of the metalloproteinases that are implicated in the tissue damage that is the hallmark of rheumatoid arthritis and other inflammatory diseases 20, 21 Moreover, Perilla oil reduces recourse to nonsteroidal anti-inflammatory drugs (NSAIDs) for analgesia in rheumatoid arthritis and thereby reduces risk for upper gastrointestinal hemorrhage. ALA rich oils appear to reduce symptoms in rheumatoid arthritis but available evidence is far less convincing than that for Perilla oil in rheumatoid arthritis ${ }^{20,21}$.

\section{CANCER BENEFITS:}

The $\omega$-3 fatty acids may suppress cancer formation, but there is no direct evidence for protective effects in humans. The essential fatty acid linoleic acid (LA) has both anti carcinogenic and antiatherogenic properties ${ }^{17,19}$. Animal studies have indicated that LA reduces the incidence of tumors induced by carcinogens. LA appears to be unique among fatty acids because low levels in the diet produce significant cancer protection ${ }^{17,19,22}$.

\section{ANTIALLERGIC BENEFITS:}

Perilla seed oil suppressed a wide range of allergic mediators in experimental animals. These findings raise the potential for Perilla oil to be effective in reducing allergic hypersensitivity in humans. The Perilla oil also showed benefits in terms of lung function, breathing parameters and may be useful for the treatment of asthma. The reduction in asthma symptoms is due to the ALA effects on leukotrienes ${ }^{9,18,21}$.

\section{NUMEROUS APPLICATIONS:}

PUFAs ( $\omega-3$ and $\omega-6,3000 \mathrm{mg} /$ day), plus multivitamins and minerals or placebo supplementation is useful in children with learning and behavioral problems. The $\omega-3$ fatty acids have been claimed to exerts neuroprotective action in Parkinson's disease and exhibit a protective effect against
Alzheimer's disease as well. High doses of $\omega-3$ FAs prevented the neurotoxin-induced decrease of dopamine that ordinarily occurs. Since Parkinson's is a disease caused by disruption of the dopamine system, this protective effect could show a promise for future research in the prevention of Parkinson's disease ${ }^{23}, 24$. Not only does Perilla contain the PUFAs, but it also a rich source of phenolic compounds, flavanoids and anthocyanins as antioxidants such as rosemarinic acid, luteolin, chrysoeriol, quercetin, catcehin and apigenin. These antioxidants may also be involved in allergy, antimicrobial, cardiovascular and cancer prevention along with the $\omega-3$ fatty acids ${ }^{25,26}$.

\section{CONCLUSION:}

Perilla oil is a viable source of vegetarian $\omega-3$ fatty acids for nutrition and health. Research showed that the incidence of heart attacks is reduced when the fats in the diet have high amount of PUFAs, especially $\omega-3$ fatty acids. These PUFAs provided protection from heart diseases. Moreover, the $\omega-3$ fatty acids decrease the blood pressure, cholesterol and glyceride contents in the blood. It also controls hematoblastic aggregation and thrombi reduction ${ }^{27,28}$ the $\omega-3$ fatty acids have inhibitory action on the growth and metabolism of breast and colon cancer. The higher intakes of $\omega^{-3}$ FAs ALA, EPA and DHA may afford some degree of protection against coronary heart diseases where the physiological potency of EPA and DHA is much greater than that for ALA ${ }^{28,30}$. Many health issues depend on a proper balance between $\omega-3$ and $\omega-6$ fatty acids. While $\omega-6$ fatty acids are necessary for normal immune function and clotting, too much $\omega-6$ fatty acid may promote abnormal clotting and an overactive immune system. It is believed that our ancestors evolved on a diet where these two omega fatty acids were approximately equal. However, modern diets usually have more $\omega-6$ fatty acids than $\omega-3$ fatty acids. Many of the chronic diseases are believed to have their origins in an imbalance of $\omega-3$ and $\omega-6$ fatty acids in diet. This necessitates that $\omega-3$ and $\omega-6$ is consumed in a balanced proportion; healthy ratios of $\omega-6: \omega-3$ range from 1:1 to $4: 1$.

\section{FUNDING:}

No funding source was used in the preparation of this manuscript.

\section{REFERENCES:}

1) Nutritional and short term toxicological evaluation of Perilla seed oil. Food Chem. 2000; 70:13-16

2) Narisawa $T$, Fukaura $Y$, Yazawa K, Ishikawa $\mathrm{C}$, et al., Colon cancer prevention with a small amount of dietary perilla oil high in alpha 
linolenic acid in an animal model. Cancer. 1994; 73(8):2069-2075.

3) Asif M, Kumar A. Nutritional and Functional Characterisations of Perilla Frutescens Seed Oil and Evaluation of Its Effect on Gastrointestinal Motility. Malay J Pharm Sci. 2010; 8 (1):1-12.

4) Reisman J, Schachter HM, Dales RE, Tran K, Kourad K, Barnes D, Sampson M, Morrison A, Gaboury I, Blackman J. Treating asthma with omega-3 fatty acids: where is the evidence? A systematic review. Medicine BMC Comp \& Alter Med. 2006; 6, 26: 1-8.

5) Mattson FH, Grundy SM. Comparison of effects of dietary saturated, monounsaturated, and polyunsaturated fatty acids on plasma lipids and lipoproteins in man. J Lipid Res. 1985; 26: 194202.

6) Green, K. N., Martinez-Coria, H., Khashwji, H., Hall, E. B., Yurko-Mauro, K. A., Ellis L, LaFerla FM. "Dietary docosahexaenoic acid and docosapentaenoic acid ameliorate amyloid- $\beta$ and tau pathology via a mechanism involving presenilin 1 levels". J Neurosci. 2007; 27(16): 4385-4395.

7) James MJ, Gibson RA, Cleland LG. Dietary polyunsaturated fatty acids and inflammatory mediator production. Am J Clin Nut. 2000; 71: 343S-348S.

8) Lewis CJ. Letter Regarding Dietary Supplement Health Claim for Omega-3 Fatty Acids and Coronary Heart Disease, http://www.cfsan.fda.gov/ dms/ds-ltr11.html and "Letter Regarding Dietary Supplement Health Claim for Omega-3 Fatty Acids and Coronary Heart Disease". U. S. Food and Drug Administration via Internet Archive, 2008.

9) Talbott SM, Hughes K. Perilla seed oil (Perilla frutescens). In: The health professional's guide to dietary supplements. Baltimore, MD: Lippincott Williams \& Wilkins 2006, 258- 260.

10) Renaud SC. The importance of the ratio of omega-6/omega-3 essential fatty acids, Biomed Pharmacotherapy. 2002; 56(8):365-379.

11) Calder PC. n-3 Fatty acids and cardiovascular disease: evidence explained and mechanisms explored. Clinical Science (Lond). 2004; 107: 1-11.

12) Schacky C, Dyerberg J. Omega-3 fatty acids. From Eskimo to clinical cardiology-what took us so long? World Rev Nutr Diet. 2001; 88:90-99.

13) Chin SF, Liu W, Storkson JM, Ha YL, Pariza MW. Dietary sources of conjugated dienoic isomers of linoleic acid, a newly recognized class of anticarcinogens. J Food Comp Anal. 1992; 5: 185-197.

14) de Lorgeril $M$, Salen $P$, Martin JL, Monjaud I, Delaye J, Mamelle N. Mediterranean diet, traditional risk factors, and the rate of cardiovascular complications after myocardial infarction. Circulation. 1999; 99:779-785.

15) Kromann N, Green A. "Epidemiological studies in the Upernavik district, Greenland. Incidence of some chronic diseases 1950-1974". Acta Medica Scandinavica. 1980; 208(5): 401406.

16) Lee KN, Kritchevsky D, Pariza MW. Conjugated linoleic acid and atherosclerosis in rabbits. Atherosclerosis. 1994; 108: 19-25.

17) Thompson H, Zhu Z, Banni S, Darcy K, Loftus T, Ip C. Morphological and biochemical status of the mammary gland is influenced by conjugated linoleic acid: implication for a reduction in mammary cancer risk. Cancer Res. 1997; 57: 5067-5072.

18) Osakabe $N$, Yasuda $A$, Natsume $M$, Yoshikawa T. Rosmarinic acid inhibits epidermal inflammatory responses: anticarcinogenic effect of Perilla frutescens extract in the murine twostage skin model. Carcinogenesis. 2004, 25(4): 549-557.

19) Ip C, Briggs SP, Haegele AD, Thompson HJ, Storkson J, Scimeca JA. The efficacy of conjugated linoleic acid in mammary cancer prevention is independent of the level or type of fat in the diet. Carcinogenesis. 1996; 17: 10451050 .

20) Banno $\mathrm{N}$, Akihisa $\mathrm{T}$, Tokuda $\mathrm{H}$, et al., Triterpene acids from the leaves of Perilla frutescens and their anti-inflammatory and antitumor-promoting effects. Biosci Biotech Biochem. 2004; 68(1): 85-90.

21) Osakabe N, Takano H, Sanbongi $C$, et al., Anti-inflammatory and anti-allergic effect of rosmarinic acid (RA); inhibition of seasonal allergic rhinoconjunctivitis (SAR) and its mechanism. Biofactors. 2005; 21:127-131.

22) Caughey GE, Mantzioris E, Gibson RA, Cleland LG, James MJ. The effect on human tumor necrosis factor and interleukin- $1 \mathrm{~b}$ production of diets enriched in n-3 fatty acids from vegetable oil or fish oil. Am J Clin Nut. 1996; 63; 116-122.

23) Azcona JO, Schang MJ, Garcia PT, Gallinger CR, Ayerza, Coates W. "Omega-3 enriched broiler meat: The influence of dietary alpha-linolenic omega-3 fatty acid sources on growth, performance and meat fatty acid composition". Canadian J Animal Sci. 2008; 88: 257-269.

24) Bemelmans $W$, Broer J, Feskens E, Smit A, Muskiet F, Lefrandt J, Bom V, May J, Meybook-de Jong B. Effect of an increased intake of a-linolenic acid and group nutritional education on cardiovascular risk factors: the Mediterranean Alpha-linolenic Enriched Groningen Dietary Intervention (MARGARIN) study. Am J Clin Nut. 2002; 75(2), 221-227. 